\title{
Effects of Decreasing the Frequency of Gonadotropin-releasing Hormone Stimulation on Gonadotropin Secretion in Gonadotropin- releasing Hormone-deficient Men and Perifused Rat Pituitary Cells
}

\author{
Joel S. Finkelstein, Thomas M. Badger, Louis St. L. O'Dea, Daniel I. Spratt, and William F. Crowley \\ Reproductive Endocrine Unit, Vincent Memorial Research Laboratories, and Departments of Medicine and Gynecology, \\ Massachusetts General Hospital, Boston, Massachusetts 02114
}

\begin{abstract}
The effects of decreasing the frequency of pulsatile gonadotropin-releasing hormone ( $\mathrm{GnRH}$ ) stimulation on pituitary responsiveness were studied in (a) men with isolated GnRH deficiency who had achieved normal sex steroid levels during prior long-term pulsatile GnRH replacement and (b) perifused dispersed pituitary cells from male rats in the absence of sex steroids. In three groups of four GnRH-deficient men, the frequency of GnRH stimulation was decreased at weekly intervals from (a) every 2-3-4 h (group I), (b) every 2-8 h without testosterone replacement (group II), or (c) every 2-8 h with testosterone replacement (group III). In three groups of three columns of perifused dispersed pituitary cells, pulses of GnRH were administered every 2,4 , or 8 h.

In groups I and II, mean area under the luteinizing hormone (LH) curve increased $(P<0.025)$ and serum testosterone levels fell $(P<0.035)$ as the frequency of $\mathrm{GnRH}$ stimulation was decreased. In group III, the area under the LH curve also increased $(P<0.01)$ although serum testosterone levels were constant, thereby demonstrating that the increase in pituitary responsiveness to slow frequencies of GnRH stimulation occurs independently of changes in the sex steroid hormonal milieu. The area under the LH curve also increased in the perifused dispersed rat pituitary cells when the frequency of GnRH administration was decreased to every 8 h $(P<0.05)$, thus demonstrating that the enhanced pituitary responsiveness to slow frequencies of $\mathbf{G n R H}$ stimulation is maintained even in the complete absence of gonadal steroids.

Nadir LH levels fell in all three groups $(P<0.01)$ as the frequency of GrRH stimulation was decreased. In contrast, mean peak $\mathrm{LH}$ levels, the rate of $\mathrm{LH}$ rise, and the rate of endogenous LH decay were constant as the frequency of GnRH stimulation was decreased. Finally, as the GnRH interpulse interval increased, mean $\mathrm{LH}$ levels fell, and mean follicle-stimulating hormone levels were stable or fell.
\end{abstract}

These results indicate that $(a)$ pituitary responsiveness to

Dr. Badger's current address is Department of Pediatrics, University of Arkansas School for Medical Sciences, Little Rock, AR 72205; Dr. Spratt's current address is Division of Endocrinology, University of Maine, Maine Medical Center, Portland, ME 04102.

Address reprint requests to Dr. Crowley, Reproductive Endocrine Unit, Bartlett Hall Extension-5, Massachusetts General Hospital, Boston, MA 02114.

Received for publication 2 July 1987 and in revised form 23 November 1987.

J. Clin. Invest.

(c) The American Society for Clinical Investigation, Inc.

0021-9738/88/06/1725/09 \$2.00

Volume 81, June 1988, 1725-1733
GnRH increases at slower frequencies of GnRH stimulation in models both in vivo and in vitro, (b) these changes in pituitary responsiveness occur independently of changes in gonadal steroid secretion; and (c) the increases in $\mathrm{LH}$ pulse amplitude and area under the curve at slow frequencies of $\mathrm{GnRH}$ stimulation are due to decreases in nadir, but not peak, LH levels. Slowing of the frequency of $\mathrm{GnRH}$ secretion may be an important independent variable in the control of pituitary gonadotropin secretion.

\section{Introduction}

The pituitary response to gonadotropin-releasing hormone (GnRH) ${ }^{1}$ is known to be determined by several factors. First, the pattern of $\mathrm{GnRH}$ presentation is critical since a pulsatile pattern of GnRH stimulation maintains normal gonadotropin secretion whereas continuous $\mathrm{GnRH}$ delivery causes profound pituitary desensitization $(1,2)$. Secondly, the quantity of GnRH within each pulse is directly related to the magnitude of the ensuing luteinizing hormone (LH) response from the pituitary $(3,4)$. Thirdly, the gonadotropin response to GnRH is modulated by the ambient levels of gonadal steroids (5-9). Finally, recent studies have demonstrated that the frequency of GnRH stimulation may itself be a critical determinant of the pituitary response to GnRH. Whereas physiological frequencies of GnRH stimulation maintain normal gonadotropin secretion in GnRH-deficient animals $(1,10,11)$ and humans (12-15), supraphysiological frequencies of $\mathrm{GnRH}$ administration produce pituitary desensitization $(1,10,16-18)$. In contrast, slow frequencies of $\mathrm{GnRH}$ stimulation increase the amplitude of the LH pulse in GnRH-deficient animals (10, $11,19)$.

To determine whether slow frequencies of GnRH secretion (a) produce an increase in pituitary responsiveness independent of changes in gonadal steroids, $(b)$ alter the relative amounts of $\mathrm{LH}$ and follicle-stimulating hormone (FSH) secreted, and $(c)$ exert a differential effect upon the various components of a gonadotropin pulse, the following experiments were performed. First, the frequency of $\mathrm{GnRH}$ administration was progressively decreased in GnRH-deficient men. This model was chosen because these men lack endogenous $\mathrm{GnRH}$ secretion yet exhibit normal pituitary responsiveness to pulsatile GnRH during long-term GnRH administration. Thus, the pituitary responsiveness to low doses of GnRH can be analyzed without interference from endogenous GnRH secretion $(14,15,20,21)$. To determine whether the observed changes in LH secretion were due to alterations in pituitary responsiveness to GnRH related to the changing frequency of GnRH

1. Abbreviations used in this paper: $\mathrm{E}_{2}$, estradiol; GnRH, gonadotropin-releasing hormone; IHH, idiopathic hypogonadotropic hypogonadism; $\mathrm{T}$, testosterone. 
stimulation, changes in gonadal steroid secretion, or a combination of both mechanisms, controlled decreases in the frequency of GnRH stimulation were performed both with and without gonadal steroid replacement. Similar experiments were conducted using perifused dispersed pituitary cells from male rats to examine the effects of decreasing the frequency of GnRH administration on gonadotropin secretion in the absence of gonadal steroids. Finally, since slow frequencies of GnRH stimulation permit a more detailed evaluation of the individual components of a gonadotropin pulse, the impact of slowed GnRH stimulation of the pituitary upon the specific characteristics of an $\mathrm{LH}$ pulse was evaluated to examine the impact of GnRH frequency upon a pulsed response.

\section{Methods}

Patient population. Eight men with idiopathic hypogonadotropic hypogonadism (IHH) aged 19-33 yr were selected on the basis of $(a)$ a failure to undergo spontaneous puberty by the age of $18,(b)$ serum $\mathrm{LH}$ concentrations $<1.0 \mathrm{mIU} / \mathrm{ml}$ and $\mathrm{FSH}$ concentrations $<3.5 \mathrm{mIU} / \mathrm{ml}$ (normal LH and FSH 3-19 mIU/ml) in the presence of serum testosterone $(\mathrm{T})$ concentrations $<100 \mathrm{ng} / \mathrm{dl}$ (normal T 300-1,000 ng/dl), (c) the absence of any endogenous gonadotropin pulsations during a 16-24-h period of baseline blood sampling at 10 -min intervals prior to GnRH therapy, $(d)$ normal basal and stimulated serum cortisol, growth hormone, thyrotropin-stimulating hormone (TSH), and prolactin concentrations after insulin-induced hypoglycemia and thyrotropin-releasing hormone injection, $(e)$ normal computed tomographic findings of the hypothalamic-pituitary region; and $(f)$ the maintenance of normal serum gonadotropin and gonadal steroid concentrations for at least 3 mo while receiving a previously reported regimen of low-dose, subcutaneous GnRH administered at 2-h intervals $(14,15)$. Four men participated in two different studies separated by at least 6 mo. The protocol was approved by the Human Studies Committee of the Massachusetts General Hospital and all subjects provided written informed consent

GnRH regimen for human studies. GnRH was administered intravenously throughout these studies since intravenous $\mathrm{GnRH}$ injections produce pituitary gonadotropin responses which more closely mimic the spontaneous LH pulses of normal men than do subcutaneous injections (22). Before taking part in the clinical protocol, each GnRH-deficient man underwent an intravenous GnRH dose-response study employing four or five intravenous $\mathrm{GnRH}$ doses ranging from 2.5 to $250 \mathrm{ng} / \mathrm{kg}$ per bolus (3). An individual dose-response curve was then constructed and the resulting $\mathrm{LH}$ pulses were compared to the range of $\mathrm{LH}$ pulse amplitudes from 20 normal men whom we studied previously $(20,23)$ to select a GnRH dose that would produce $\mathrm{LH}$ pulses with amplitudes within the midrange of those in the normal male population. On the basis of these dose-response studies, the "physiologic" doses of GnRH employed in this study ranged from 11 to $50 \mathrm{ng} / \mathrm{kg}$ per bolus. GnRH was initially administered every $2 \mathrm{~h}$ because this is the average $\mathrm{LH}$ interpulse interval observed in normal men (23-25).

Experiment 1. Four IHH men (group I) were evaluated during three admissions each separated by $7 \mathrm{~d}$. On the first day of the study (day 1) an indwelling catheter was inserted into a forearm vein to convert patients from long-term subcutaneous $\mathrm{GnRH}$ administration to intravenous $\mathrm{GnRH}$ injected at 2-h intervals by an autoinfusion pump (Ferring Laboratories Inc., Ridgewood, NJ). Subsequently, they returned for three admissions to the Clinical Research Center (CRC) at the Massachusetts General Hospital during which four GnRH pulses were monitored. In order to analyze the same number of pulses during each admission, the length of the sampling interval was progressively increased as the GnRH-interpulse interval was increased. The first admission occurred $3 \mathrm{~d}$ later (day 4 ) during which $\mathrm{GnRH}$ was injected intravenously at $2-\mathrm{h}$ intervals for $8 \mathrm{~h}(n=$ four pulses). The patients were then discharged receiving intravenous $\mathrm{GnRH}$ every $3 \mathrm{~h}$ from the infusion pumps for the intervening $7 \mathrm{~d}$. During the second admission, (day 11), GnRH was injected every $3 \mathrm{~h}$ for $12 \mathrm{~h}$ ( $n=$ four pulses). The patients were then discharged while receiving GnRH every $4 \mathrm{~h}$ for the next $7 \mathrm{~d}$. During the third admission (day 18), GnRH was injected every $4 \mathrm{~h}$ for $16 \mathrm{~h}$ ( $n=$ four pulses). Serum gonadotropin concentrations were determined at times $0,5,10,15,20,30,40,60,80,100$, and $120 \mathrm{~min}$ after each GnRH dose. When the interval between GnRH doses was longer than $120 \mathrm{~min}$, sampling was then continued every 30 min until the next $\mathrm{GnRH}$ dose. Serum $\mathrm{T}$ and estradiol $\left(\mathrm{E}_{2}\right)$ concentrations were determined on serum pools composed of equal aliquots of each sample obtained during an admission.

Experiment 2. Four IHH men (group II) were converted from long-term subcutaneous $\mathrm{GnRH}$ to intravenous $\mathrm{GnRH}$ as in experiment 1 . On day 4 , the patients were admitted to the CRC and intravenous GnRH was injected at $2 \mathrm{~h}$ intervals for $8 \mathrm{~h}$ ( $n=$ four pulses). The patients were then discharged receiving intravenous GnRH every $8 \mathrm{~h}$ for the next $7 \mathrm{~d}$. On day 11 , the patients were readmitted to the CRC and GnRH was injected every $8 \mathrm{~h}$ for $32 \mathrm{~h}$ ( $n=$ four pulses). Serum gonadotropins and gonadal steroids were determined as in experiment 1 with an additional sample drawn 90 min after each GnRH dose.

Experiment 3. GnRH was administered to four additional IHH men (group III) as in experiment 2. However, at the end of the first blood sampling period, all patients received an intramuscular injection of testosterone enanthate (100 mg). Serum LH, FSH, T, and $E_{2}$ levels were determined as in experiment 2.

Experiment 4. Pituitaries from adult male rats having a mean weight of $316 \mathrm{~g}$ were dispersed and prepared for perifusion as previously reported (26). Briefly, the pituitaries were enzymatically dispersed, mixed with Biogel P-2 (Bio-Rad Laboratories, Richmond, CA), and packed into columns of 10 million cells each. Medium was pumped through the columns overnight and experiments were performed between 18 and $24 \mathrm{~h}$ after dispersion. In all experiments, the medium containing fetal calf serum was replaced with a Krebs-Ringer bicarbonate buffer containing bovine serum albumin.

In each experiment, $50 \mathrm{ng} / \mathrm{ml} \mathrm{GnRH}$ was introduced as discrete pulses lasting $3.3 \mathrm{~min}$. There were three columns per group. GnRH pulses were introduced every 2,4 , or $8 \mathrm{~h}$ for $48 \mathrm{~h}$ and fractions were collected to determine the LH secretory response.

Evaluation of pituitary gonadotropin and gonadal steroid secretion. To determine the effects of slowing the frequency of GnRH stimulation on pituitary responsiveness in the three human experiments, the following parameters of gonadotropin secretion were evaluated during each sampling period: $(a)$ mean LH pulse amplitude, $(b)$ mean area under the LH curve, and (c) mean serum LH and FSH concentrations. The pulse amplitude was defined as the difference between peak and nadir LH concentrations. The area under the LH curve was determined by a previously described computer program that attempts to correct for (a) prior LH secretion that has yet to be cleared, $(b) \mathrm{LH}$ that would have contributed to the total area had the next pulse not occurred, and $(c)$ the presence of a constant baseline (3). To ensure comparability of results, the area under the curve was determined using only the first $2 \mathrm{~h}$ of data for each LH pulse regardless of the GnRH frequency. Arithmetic means of the serum LH and FSH concentrations were determined over the entire GnRH-interpulse interval using a computer program designed to weight values appropriately for differences in sampling intervals. For the perifused dispersed rat pituitary cells, the area under the LH pulse was used to quantitate the amount of LH secreted in response to each GnRH bolus.

To determine the components of the LH pulses which were responsible for changes in LH pulse amplitude and area under the curve, the following additional parameters were evaluated for each sampling period: $(a)$ mean peak LH levels, $(b)$ mean nadir LH levels, $(c)$ mean slopes of the rising component of the LH curve, and $(d)$ mean rates of LH decay $(k)$. Decay constants were determined from a computer program that utilized the log-transformed data to construct a linear regression model of hormonal decay. At frequencies slower than every $2 \mathrm{~h}$, decay constants were determined using only the first $2 \mathrm{~h}$ of each LH pulse. 
Statistical analysis. Because mean gonadotropin levels rise and mean LH pulse amplitudes fall when GnRH frequency is progressively increased in GnRH-deficient men (16), we hypothesized that mean gonadotropin levels would fall and mean $\mathrm{LH}$ amplitudes and areas under the curve would rise when the frequency of GnRH administration was decreased in these men. Therefore, differences were analyzed with one-tailed statistics using analysis of covariance for experiment I and paired $t$-testing for experiments II and III. To determine whether gonadal steroid replacement altered the effects induced by slowing the GnRH frequency, the differences in LH pulse amplitude and area under the curve in groups II and III were compared by a two-tailed $t$ test. For the perifused dispersed pituitary cells, the areas under the curve at each of the three GnRH frequencies were compared by a one-tailed $t$ test. $P$ values $<0.05$ are construed as statistically significant. However, because of the small number of patients in each group, all $P$ values $<0.1$ are reported and $P$ values between 0.05 and 0.1 are construed as being suggestive of statistical significance. All data are reported as the mean \pm SEM.

Radioimmunoassays. Serum LH and FSH concentrations were determined by previously described double-antibody radioimmunoassays using the Second International Reference Preparation (Second IRP) as the reference standard for the human subjects and rat LH Reference Preparation 2 (RP-2) as the reference standard for the in vitro studies $(26,27)$. All samples from an individual patient were analyzed in the same assay. Serum $\mathrm{T}$ and $\mathrm{E}_{2}$ concentrations were also determined by previously described radioimmunoassays $(28,29)$. The interassay and intra-assay coefficients of variation were $<10 \%$ for the $L H$ and FSH radioimmunoassays and $<15 \%$ for the $T$ and $E_{2}$ radioimmunoassays.

\section{Results}

Experiment 1 . The pituitary $\mathrm{LH}$ responses to progressive decreases in the frequency of $\mathrm{GnRH}$ administration in a representative patient in group I are illustrated in Fig. 1. In this individual, when the GnRH frequency was decreased to every $4 \mathrm{~h}$, there appeared to be a fall in nadir LH levels but little change in peak LH levels resulting in an increase in LH pulse amplitude and area under the curve. For the four group I patients, both $\mathrm{LH}$ pulse amplitude $(P<0.01)$ and area under the curve $(P<0.02)$ increased when the frequency of GnRH administration was decreased, largely due to changes occurring when the GnRH frequency was slowed from every 3-4 h (Fig. 2 and Table I). Mean LH levels fell as the frequency of GnRH administration was decreased $(P<0.02)$ while mean FSH concentrations did not change (Table I). Both serum $\mathrm{T}(P<$ $0.035)$ and $\mathrm{E}_{2}(P<0.025)$ concentrations fell when the frequency of GnRH administration was decreased, with the fall in serum T levels occurring at the 4-h GnRH interval (Table I).

Experiment 2. The $\mathrm{LH}$ responses of a representative patient in group II are shown in Fig. 3 (upper panel), demonstrat- ing an increase in both $\mathrm{LH}$ pulse amplitude and area under the curve when the GnRH frequency was decreased to every $8 \mathrm{~h}$ in this individual. In the four group II patients, both LH pulse amplitude and area under the curve increased when $\mathrm{GnRH}$ was administered every $8 \mathrm{~h}$ although the change in LH amplitude did not reach statistical significance $(P<0.06$ for amplitude; $P<0.025$ for area; Fig. 4 and Table II). Mean FSH levels fell $(P<0.02)$ and there was a suggestion of a fall in mean $\mathrm{LH}$ levels $(P<0.06)$. Serum T concentrations fell $(P<0.01)$ and there was a suggestion of a fall in serum $\mathrm{E}_{2}$ concentrations $(P$ $<0.07$ ) as the GnRH frequency was decreased from every $2 \mathrm{~h}$ to every $8 \mathrm{~h}$ (Fig. 4 and Table II).

Experiment 3. To determine whether the changes in gonadotropin secretion observed above were due to an increase in pituitary sensitivity to slower frequencies of $\mathrm{GnRH}$ stimulation or a decrease in the negative feedback effects of sex steroids at the pituitary level, GnRH was administered as in experiment 2 to four additional IHH men (group III) while serum $\mathrm{T}$ levels were maintained with exogenous $\mathrm{T}$ replacement. Fig. 3 (lower panel) shows the LH responses of one of the four patients in group III demonstrating that both $\mathrm{LH}$ pulse amplitude and area under the curve increased when the frequency of $\mathrm{GnRH}$ stimulation was slowed despite maintaining similar serum $\mathrm{T}$ levels. In the four group III patients, both LH pulse amplitude $(P<0.03)$ and area under the curve $(P$ $<0.01$ ) increased as $\mathrm{GnRH}$ stimulation was decreased to every $8 \mathrm{~h}$ despite maintenance of normal gonadal steroid levels (Fig. 4 and Table II). The net increase in LH pulse amplitude $(8.6 \pm 2.8 \mathrm{mIU} / \mathrm{ml}$ for group III vs. $15.0 \pm 7.1 \mathrm{mIU} / \mathrm{ml}$ for group II; $P>0.2)$ and area under the curve $(603 \pm 62 \mathrm{mIU} / \mathrm{ml} \times \mathrm{min}$ for group III vs. $1,344 \pm 396 \mathrm{mIU} / \mathrm{ml} \times$ min for group II; $P$ $>0.15$ ) were statistically similar in the patients who received $T$ replacement when the frequency of GnRH administration was slowed from every 2 to $8 \mathrm{~h}$ and in the men in whom the GnRH frequency was similarly slowed in the absence of gonadal steroid replacement. Mean $\mathrm{LH}$ and FSH levels both fell ( $P$ $<0.01$ ) when the GnRH frequency was decreased to every $8 \mathrm{~h}$ (Table II). Because of exogenous $\mathrm{T}$ replacement, there were no differences between serum $T$ or $E_{2}$ levels as the GnRH frequency was decreased from every $2 \mathrm{~h}$ to every $8 \mathrm{~h}$ (Fig. 4 and Table II).

Experiment 4. To further elucidate the effects of decreasing the frequency of $\mathrm{GnRH}$ administration on pituitary responsiveness without the modulatory actions of gonadal steroids, a similar experiment was performed in an in vitro system in which rat anterior pituitary cells were dispersed as described above. Fig. 5 depicts the LH secretory pattern of columns (n $=$ three per group) receiving $50 \mathrm{ng}$ of $\mathrm{GnRH}$ every 2,4 , or $8 \mathrm{~h}$.

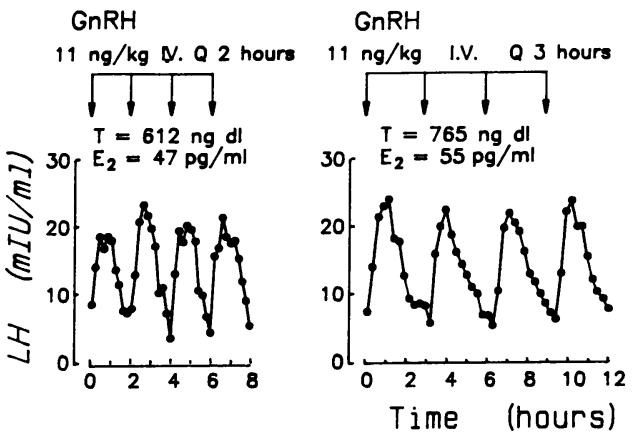

Figure 1. Serum LH concentrations determined at frequent intervals in one man with isolated $\mathrm{GnRH}$ deficiency as the frequency of $\mathrm{GnRH}$ administration was decreased from every 2 to 3 to $4 \mathrm{~h}$ at weekly intervals. Testosterone $(T)$ and estradiol $\left(E_{2}\right)$ concentrations determined on serum pools from each sampling period are indicated on the figure. 

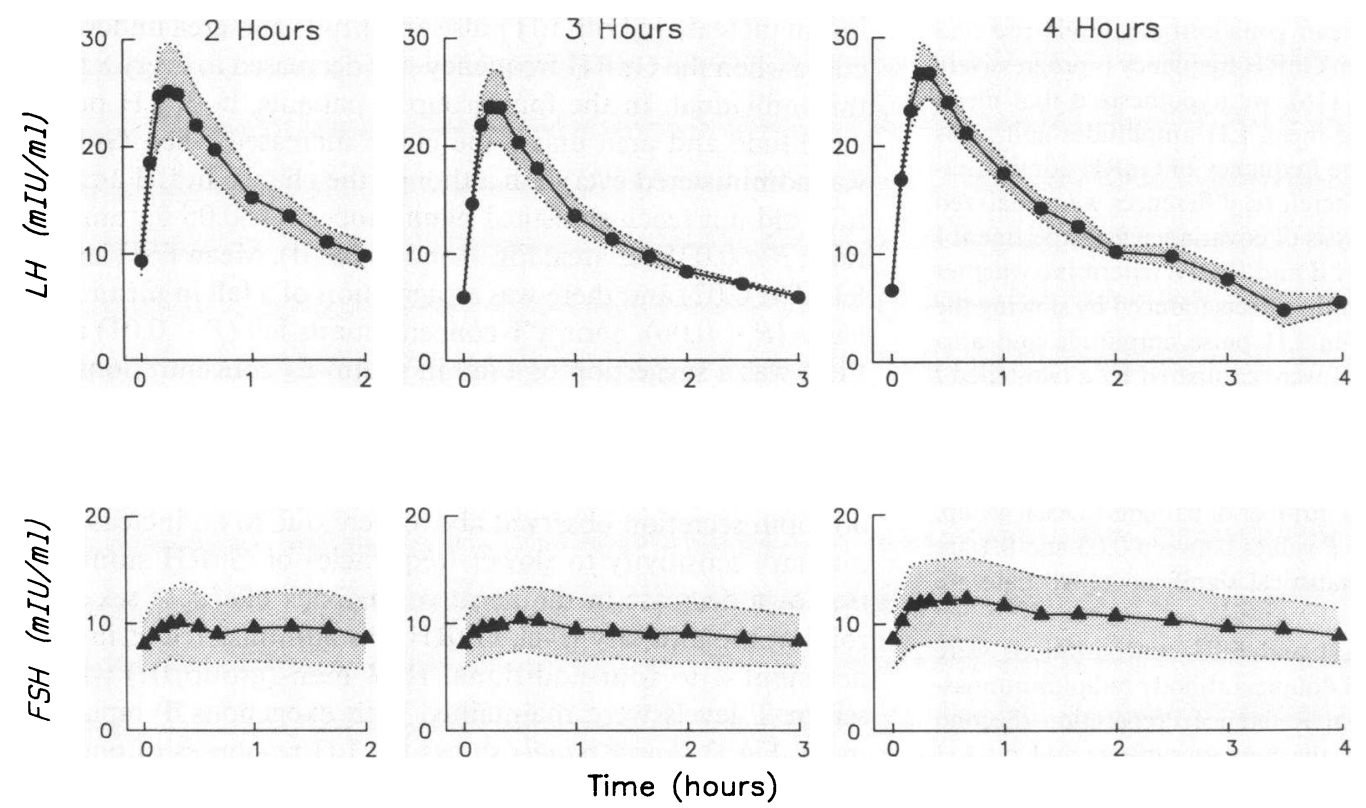

Figure 2. Mean ( \pm SEM) serum LH and FSH concentrations of four GnRH-induced pulses in four men when GnRH was administered every 2,3 , or $4 \mathrm{~h}$.

The LH response to the initial bolus of each column did not differ significantly. After 34 and $42 \mathrm{~h}$ of stimulation, the $\mathrm{LH}$ responses to pulsatile GnRH given every $8 \mathrm{~h}$ were significantly greater than the responses to GnRH given every 2 or $4 \mathrm{~h}(P$ $<0.05)$. Because many of the baseline FSH levels were below the limit of assay sensitivity, conclusions about changes in FSH secretion could not be made in this system.

Analysis of components of $\mathrm{LH}$ pulsations in response to decreases in $G n R H$ frequency. Slowing the frequency of GnRH administration allowed individual LH pulses to be dissected more precisely so that a detailed analysis of peak $\mathrm{LH}$ levels, nadir LH levels, the time to peak LH levels, and the rates of LH decay was possible. In all three groups of patients, the increases in LH pulse amplitude and area under the curve observed during slowing of the GnRH stimulation were due

Table I. Gonadotropin and Gonadal Steroid Responses in Four IHH Men to Decreases in GnRH Frequency from Every 2 to 3 to $4 \mathrm{~h}$

\begin{tabular}{lccc}
\hline & \multicolumn{3}{c}{ GnRH frequency* } \\
\cline { 2 - 4 } \multicolumn{1}{c}{ Hormone } & 2 & 3 & 4 \\
\hline & \multicolumn{3}{c}{$h$} \\
Mean LH $(\mathrm{mIU} / \mathrm{ml})^{\ddagger}$ & $16.3 \pm 2.4$ & $12.2 \pm 1.2$ & $12.4 \pm 1.1$ \\
Mean FSH $(\mathrm{mIU} / \mathrm{ml})$ & $9.4 \pm 3.2$ & $9.2 \pm 2.7$ & $10.5 \pm 3.2$ \\
Mean LH amplitude & & & \\
$\quad(m I U / m l)^{8}$ & $17.0 \pm 3.5$ & $18.3 \pm 2.9$ & $22.0 \pm 1.9$ \\
Mean area under LH curve & & & \\
$\quad(m I U / m l \times m i n)^{\ddagger}$ & $1,554 \pm 243$ & $1,565 \pm 154$ & $2,085 \pm 221$ \\
Mean T $(n g / d l)^{\| 1}$ & $583 \pm 79$ & $614 \pm 84$ & $373 \pm 43$ \\
Mean $\mathrm{E}_{2}(\mathrm{pg} / \mathrm{ml})^{\top}$ & $52.1 \pm 12.5$ & $38.7 \pm 7.3$ & $25.8 \pm 3.4$ \\
& & & \\
\hline
\end{tabular}

* All $P$ values analyzed by analysis of covariance from 2 to 3 to $4 \mathrm{~h}$.

$¥ P<0.02$.

${ }^{8} P<0.01$.

" $P<0.035$.

' $P<0.025$. entirely to decreases in nadir LH levels $(P<0.01$ for all comparisons; Fig. 2 and 4 and Table III). In striking contradistinction to the fall in nadir LH levels, peak LH levels did not change as the frequency of GnRH stimulation was decreased despite marked changes in sex steroid levels (Figs. 2 and 4 and Table III). The slopes of the rising component of LH secretion and the decay constants for $\mathrm{LH}$ during the first $2 \mathrm{~h}$ of sampling were identical regardless of the frequency of $\mathrm{GnRH}$ stimulation or the sex steroid hormone milieu (Figs. 2 and 4; Table III).

\section{Discussion}

In this study, we have demonstrated that controlled decreases in the frequency of administration of physiologic doses of GnRH to GnRH-deficient men have profound effects in and of themselves on pituitary gonadotropin secretion. When the frequency of GnRH stimulation was slowed, LH pulse amplitude and area under the curve both increased. This finding suggested that pituitary responsiveness to $\mathrm{GnRH}$ increases when the GnRH frequency is slowed in the setting of physiological levels of gonadal steroids and is consistent with results in experimental systems where gonadal steroids were absent $(10,11,19,30-32)$. However, mean gonadal steroid levels also fell at the GnRH frequencies associated with increases in LH pulse amplitude and area. Because gonadal steroids can inhibit pulsatile LH secretion at the pituitary level in the human male (5-9), it was thus not possible to determine whether the larger LH pulses induced by decreasing the frequency of $\mathrm{GnRH}$ administration solely reflected a primary alteration in pituitary responsiveness to slow frequencies of $\mathrm{GnRH}$ administration, a reduced negative feedback effect of sex steroids, or both, in a setting where serum sex steroid levels were lower. Therefore, similar studies were performed in other GnRH-deficient men while maintaining serum sex steroid levels with exogenous $T$ and in perifused dispersed rat pituitary cells in the absence of gonadal steroids. In both of these experiments, LH pulse amplitude and area under the secretory curve increased as the frequency of GnRH stimulation was slowed, thus demonstrat- 

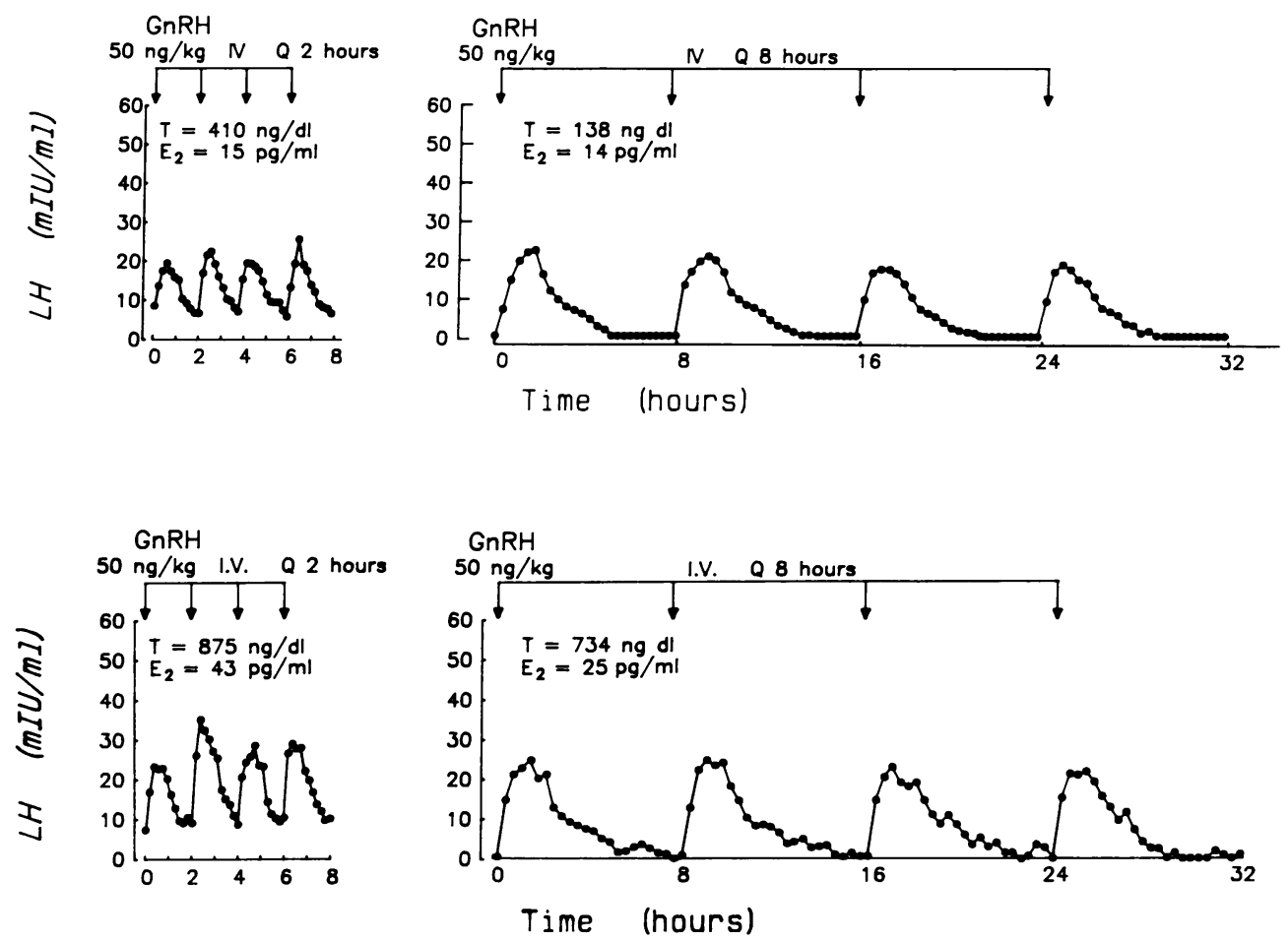

Figure 3. Serum LH concentrations determined at frequent intervals in two men with isolated GnRH deficiency as the frequency of GnRH administration was decreased from every 2 to every $8 \mathrm{~h}$ at weekly intervals without $\mathrm{T}$ replacement (upper panel) or with $\mathrm{T}$ replacement (lower panel). $\mathrm{T}$ and $\mathrm{E}_{2}$ concentrations determined on serum pools from each sampling period are indicated on the figure.

ing that slow frequencies of GnRH administration per se can modulate pituitary gonadotropin secretion independent of changes in gonadal steroid feedback.

Because discrete $\mathrm{LH}$ pulsations are easily distinguishable at slow frequencies of GnRH stimulation, this model provides a unique opportunity to examine the components of an individ- ual LH secretory event responsible for the observed changes in pulsatile LH secretion. The increases in both LH pulse amplitude and area under the curve occurring at slower GnRH frequencies were largely attributable to a decreasing baseline level of gonadotropin secretion since peak LH levels were well maintained and neither the slope of the rising component of
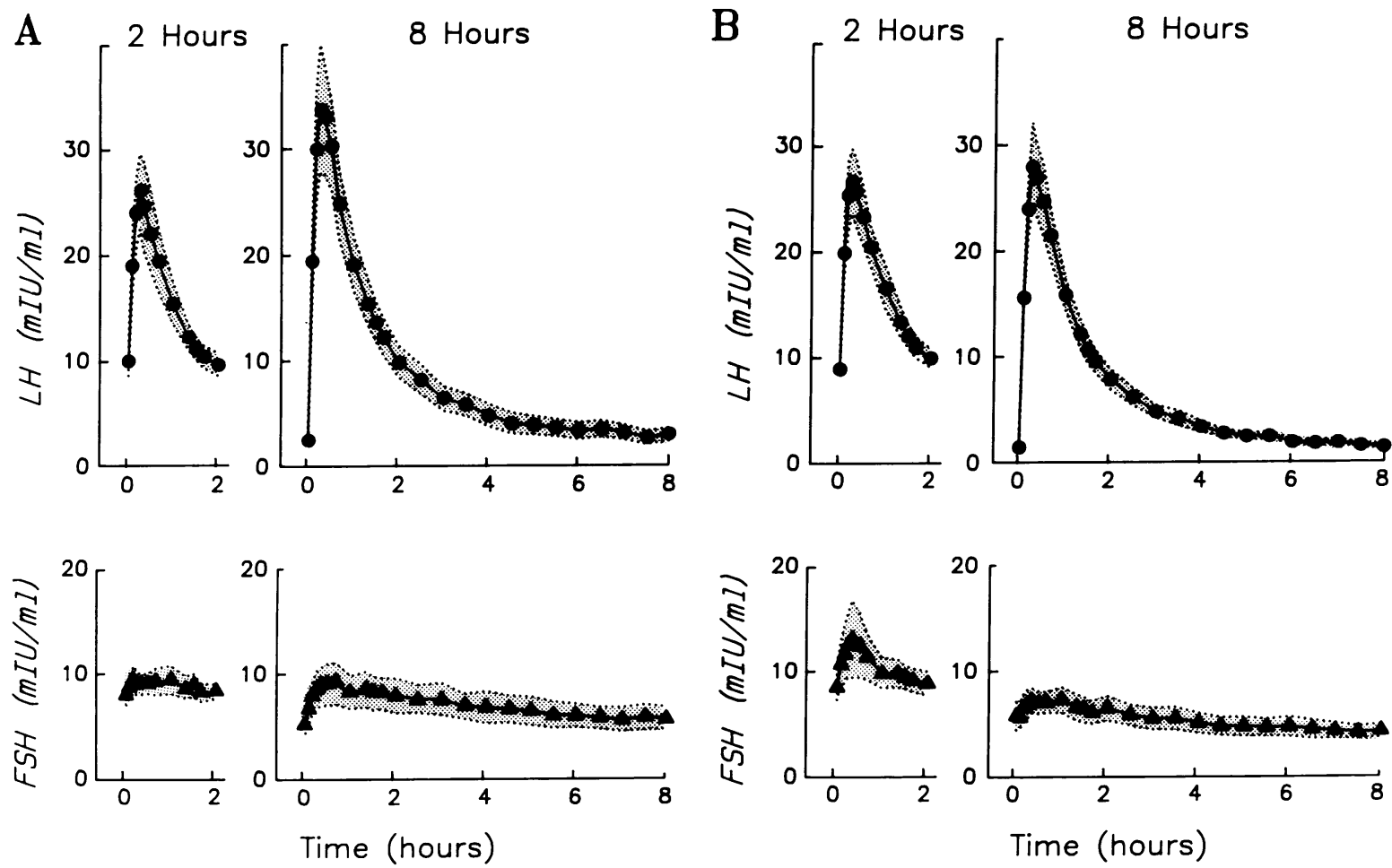

Figure 4. Mean ( \pm SEM) serum LH and FSH concentrations of four GnRH-induced pulses in four men when GnRH was administered every 2 or every $8 \mathrm{~h}(A)$ without $\mathrm{T}$ replacement or $(B)$ with $\mathrm{T}$ replacement. 
Table II. Gonadotropin and Gonadal Steroid Responses in Two Groups of Four IHH Men to Decreases in GnRH Frequency from Every 2 to $8 \mathrm{~h}$ with and without T Replacement

\begin{tabular}{|c|c|c|c|c|}
\hline \multirow[b]{3}{*}{ Hormone } & \multicolumn{4}{|c|}{ GnRH frequency $(h)$} \\
\hline & \multicolumn{2}{|c|}{ Without T } & \multicolumn{2}{|c|}{ With T } \\
\hline & 2 & 8 & 2 & 8 \\
\hline Mean LH $(m I U / m l)$ & $18.1 \pm 4.1$ & $8.5 \pm 1.4^{*}$ & $16.8 \pm 1.8$ & $6.5 \pm 0.7^{* *}$ \\
\hline Mean FSH $(m I U / m l)$ & $8.8 \pm 1.1$ & $6.9 \pm 1.4^{\ddagger}$ & $9.3 \pm 1.1$ & $5.3 \pm 0.9^{* *}$ \\
\hline Mean LH amplitude $(\mathrm{mI} U / \mathrm{ml})$ & $17.1 \pm 3.4$ & $32.1 \pm 5.4^{*}$ & $18.6 \pm 2.8$ & $27.1 \pm 4.2^{\ddagger \ddagger}$ \\
\hline Mean area under LH curve $(\mathrm{mIU} / \mathrm{ml} \times \mathrm{min})$ & $1,488 \pm 149$ & $2,832 \pm 412^{8}$ & $1,769 \pm 279$ & $2,372 \pm 230^{* *}$ \\
\hline Mean T $(n g / d l)$ & $713 \pm 118$ & $197 \pm 48^{\prime \prime}$ & $570 \pm 144$ & $553 \pm 112$ \\
\hline Mean $\mathrm{E}_{2}(\mathrm{pg} / \mathrm{ml})$ & $35.7 \pm 9.3$ & $19.4 \pm 2.8^{\prime}$ & $30.6 \pm 5.6$ & $26.8 \pm 2.9$ \\
\hline
\end{tabular}

${ }^{*} P<0.06$ vs. 2 h without T. ${ }^{\ddagger} P<0.02$ vs. 2 h without T. ${ }^{8} P<0.025$ vs. 2 h without T. $\quad P<0.01$ vs. 2 h without T. ' $P<0.07$ vs. 2 h without T. $* * 0<0.01$ vs. 2 h with T. ${ }^{\sharp} P<0.03$ vs. 2 h with T.

LH secretion nor the rate of LH decay changed at any given GnRH frequency or sex steroid milieu.

One surprising feature of these studies was the remarkable preservation of peak LH levels over a wide range of GnRH frequencies and in the settings of both normal and low levels of gonadal steroids. Although it is not currently known why peak LH levels are maintained as the frequency of GnRH administration is decreased in the male in vivo, the constancy of peak LH levels in GnRH-deficient men in response to identical bolus doses of GnRH indirectly suggests that any variability in peak LH levels observed in normal men is due to variations in the amount or variability in the timing of endogenous GnRH secretion as has been described in animal systems (4). The maintenance of the rate of LH decay is less surprising since this component of LH pulses is felt to represent the metabolic clearance of $\mathrm{LH}$ which does not show any major changes in humans over a wide range of physiological circumstances (33).

Whereas LH pulse amplitude and area under the curve both increased when the frequency of GnRH stimulation was slowed, mean LH levels decreased and mean FSH levels did not change when the GnRH frequency was slowed from every 2 to 3 to $4 \mathrm{~h}$. However, when the GnRH frequency was slowed

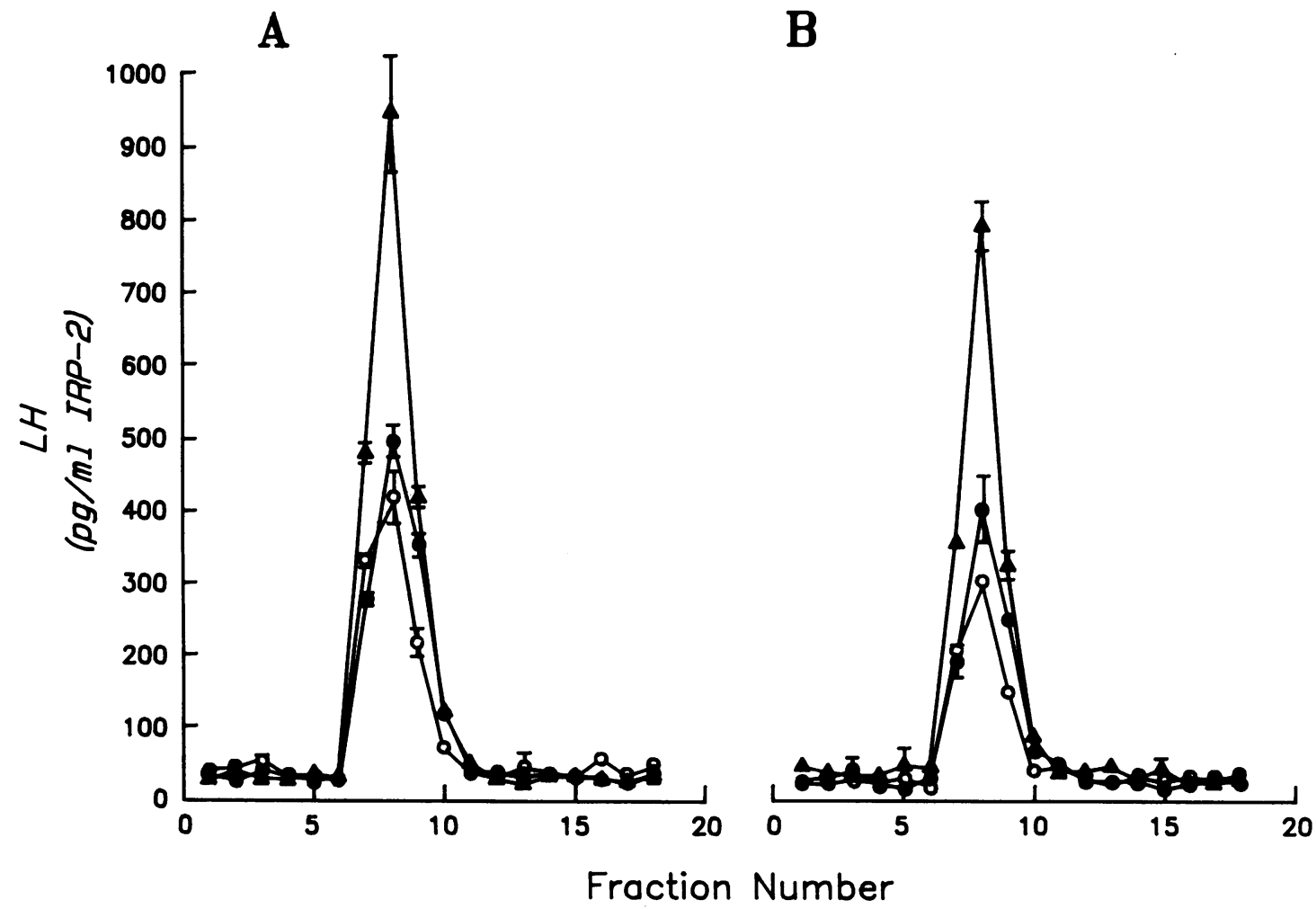

Figure 5. Mean ( \pm SEM) serum LH concentrations of three columns of perifused rat pituitary cells receiving pulses of GnRH every 2 (0), $4(\bullet)$, or $8 \mathrm{~h}(\Delta)$. In $A$, each column had received $\mathrm{GnRH}$ at the designated frequency for $34 \mathrm{~h}$ whereas in $B$, each column had received $\mathrm{GnRH}$ at the designated frequency for $42 \mathrm{~h}$. 
Table III. Mean Peak LH Levels, Nadir LH Levels, Slope of the Rising Component of LH Secretion, and Rate of LH Decay in Four IHH Men in Response to Decreases in GnRH Frequency

\begin{tabular}{|c|c|c|c|c|c|c|c|}
\hline \multirow[b]{3}{*}{ Level } & \multicolumn{7}{|c|}{ GnRH frequency $(h)$} \\
\hline & \multicolumn{3}{|c|}{ Group I } & \multicolumn{2}{|c|}{ Group II } & \multicolumn{2}{|c|}{ Group III } \\
\hline & 2 & 3 & 4 & 2 & 8 & 2 & 8 \\
\hline Mean peak LH $(m I U / m l)$ & $26.2 \pm 4.6$ & $24.2 \pm 3.2$ & $27.6 \pm 2.4$ & $27.1 \pm 4.1$ & $35.3 \pm 5.8$ & $27.2 \pm 3.0$ & $28.6 \pm 4.3$ \\
\hline Mean nadir $\mathrm{LH}(\mathrm{mIU} / \mathrm{ml})^{*}$ & $9.3 \pm 1.3$ & $6.0 \pm 0.4$ & $5.8 \pm 0.8$ & $9.9 \pm 1.4^{\ddagger}$ & $2.6 \pm 0.5$ & $8.6 \pm 0.4^{\ddagger}$ & $1.5 \pm 0.1$ \\
\hline Mean slope of LH rise $\left(\mathrm{mIU} / \mathrm{ml} \times \mathrm{min}^{-1}\right)$ & $1.2 \pm 0.2$ & $1.1 \pm 0.2$ & $1.2 \pm 0.2$ & $1.1 \pm 0.2$ & $1.9 \pm 0.5$ & $1.3 \pm 0.2$ & $1.5 \pm 0.2$ \\
\hline Mean LH decay constant $\left(\times 10^{-2}\right)$ & $-1.2 \pm 0.1$ & $-1.3 \pm 0.1$ & $-1.2 \pm 0.1$ & $-1.4 \pm 0.3$ & $-1.3 \pm 0.0$ & $-1.3 \pm 0.1$ & $-1.3 \pm 0.1$ \\
\hline
\end{tabular}

$* P<0.01$ by analysis of covariance from every $2-3-4 \mathrm{~h} . \quad{ }^{\ddagger} P<0.01 \mathrm{vs} .8 \mathrm{~h}$.

further, to every $8 \mathrm{~h}$, a decrease in mean FSH levels was also demonstrated. Because mean gonadotropin concentrations are influenced both by changes in pituitary responsiveness (as reflected by pulse amplitude and area) as well as the frequency of GnRH administration, mean gonadotropin concentrations can fall even if pituitary responsiveness increases if the frequency of GnRH administration is decreased sufficiently. Had only mean LH levels been determined in our study, we would have concluded that pituitary responsiveness decreased at slower frequencies of GnRH administration. However, the large increases in LH pulse amplitude and area under the curve at the slower frequencies of $\mathrm{GnRH}$ administration clearly demonstrate that pituitary responsiveness to $\mathrm{GnRH}$ increases as the frequency of GnRH stimulation is decreased and that it is essential to dissect the various components of a secretory curve in experimental circumstances.

Previous investigations of the effects of decreases in GnRH frequency on mean gonadotropin levels have produced conflicting results that appear to be related to the degree of gonadal maturation in the model under investigation. Studies employing gonadally intact, mature monkeys have demonstrated a fall in mean LH levels with no change in mean FSH levels, similar to that seen in our study, when the frequency of GnRH stimulation was decreased $(34,35)$. However, studies utilizing castrate or gonadally immature models have reported a disproportionate rise in serum FSH compared with LH levels at slower frequencies of $\mathrm{GnRH}$ administration $(10,11,18,36$, 37). For example, Gross et al. (36) recently reported a disproportionate rise in serum FSH levels when the frequency of GnRH stimulation was decreased in GnRH-deficient men whose serum $T$ levels were in the hypogonadal range since they had not received prior long-term GnRH therapy. Because the early stages of puberty are characterized by a predominance of FSH as compared with LH secretion (38), and since we have previously documented that pituitary priming is occurring during this period of GnRH administration (39), the preferential rise in mean FSH levels in the study of Gross et al. (36) may well reflect the normal physiological response of the pituitary to GnRH stimulation during early puberty when gonadal secretory influences are low. In addition, Adams et al. (37) have recently reported that testosterone replacement prevents this preferential secretion of FSH in response to slow frequencies of GnRH administration in orchidectomized juvenile monkeys. Consequently, in our gonadally mature patients, the failure to elicit a preferential rise in FSH secretion in response to slow frequencies of $\mathrm{GnRH}$ administration may be explained either by their normal sex steroid secretion or by inhibin production by the mature gonad.

The cellular mechanisms by which slow frequencies of GnRH administration alter pituitary responsiveness are unknown. In GnRH-deficient male rats, the number of GnRH receptors falls when the frequency of $\mathrm{GnRH}$ stimulation is slowed (18) so that it is unlikely that the increases in LH pulse amplitude and area in our patients are due to changes in GnRH receptor number. The increased LH pulse amplitude and area under the curve that we observed at slow frequencies of GnRH administration might reflect an increase in readily dischargable LH, as has been suggested in animal models (19). Whether other mechanisms, such as alterations in gonadotropin synthesis or postreceptor events, are involved in the changes in pituitary responsiveness at slow GnRH frequencies is presently unknown.

In summary, we have demonstrated that slow frequencies of $\mathrm{GnRH}$ administration produce an increase in pituitary responsiveness that is primarily due to a fall in nadir LH levels with no change in peak LH levels, and is independent of changes in gonadal steroid secretion. Because there is considerable heterogeneity in the frequency of endogenous GnRH secretion in normal men $(20,23)$, it is possible that a compensatory increase in the magnitude of $\mathrm{LH}$ secretion helps to maintain normal gonadal steroid secretion during long, spontaneous pauses in endogenous GnRH secretion. Similarly, it is possible that an increase in pituitary responsiveness to slow frequencies of GnRH stimulation is important in the production of the large-amplitude $\mathrm{LH}$ pulsations that are characteristic of the luteal phase of the normal menstrual cycle $(27,40)$. Alterations in the frequency of $\mathrm{GnRH}$ stimulation are an important determinant of pituitary responsiveness in GnRH-deficient men and may also play an important role in the control of gonadotropin secretion in normal men and women.

\section{Acknowledgments}

We gratefully acknowledge the staff of the Mallinckrodt General Clinical Research Center for their meticulous performance of the protocols; Ms. Sandra Bruvers, Ms. Linda Committo, Ms. Elizabeth Flynn, Mr. Thomas Marcotti, and Ms. Francine Monahan for performance of the radioimmunoassays; and Ms. Jan Campbell and Ms. Donna Peltier-Saxe for their devoted care of the patients.

This work was supported by grants HD-15788, HD-18169, RR-1066, and T32-AM-07028 from the National Institutes of Health and by the Vincent Research Fund. 


\section{References}

1. Belchetz, P. E., T. M. Plant, Y. Nakai, E. J. Keogh, and E. Knobil. 1978. Hypophysial responses to continuous and intermittent delivery of hypothalamic gonadotropin-releasing hormone. Science (Wash. DC). 202:631-633.

2. Crowley, W. F., F. Comite, W. Vale, J. Rivier, D. L. Loriaux, and G. B. Cutler. 1981. Therapeutic use of pituitary desensitization with a long-acting LHRH agonist: a potential new treatment for idiopathic precocious puberty. J. Clin. Endocrinol. Metab. 52:370-372.

3. Spratt, D. I., J. S. Finkelstein, T. M. Badger, J. P. Butler, and W. F. Crowley, Jr. 1986. Bio- and immunoactive luteinizing hormone responses to low doses of gonadotropin-releasing hormone (GnRH): dose-response curves in GnRH-deficient men. J. Clin. Endocrinol. Metab. 63:143-150.

4. Levine, J. E., K. F. Pau, V. D. Ramirez, and G. L. Jackson. 1982. Simultaneous measurement of luteinizing hormone-releasing hormone and luteinizing hormone release in unanesthetized, ovariectomized sheep. Endocrinology. 111:1449-1455.

5. Santen, R. 1975. Is aromitization of testosterone to estradiol required for inhibition of luteinizing hormone secretion in men? $J$. Clin. Invest. 56:1555-1563.

6. Lasley, B. L., C. F. Wang, and S. S. C. Yen. 1976. Assessments of the functional capacity of the gonadotrophs in men: effects of estrogen and clomiphene. J. Clin. Endocrinol. Metab. 43:182-189.

7. Winters, S. J., J. J. Janick, D. L. Loriaux, and R. J. Sherins. 1979. Studies on the role of sex steroids in the feedback control of gonadotropin concentrations in men. II. Use of the estrogen antagonist clomiphene citrate. J. Clin. Endocrinol. Metab. 48:222-227.

8. Valk, T. W., K. P. Corley, R. P. Kelch, and J. C. Marshall. 1981. Pulsatile gonadotropin-releasing hormone in gonadotropin-deficient and normal men: suppression of follicle-stimulating hormone responses by testosterone. J. Clin. Endocrinol. Metab. 53:184-191.

9. Veldhuis, J. D., A. D. Rogol, E. Samojlik, and N. H. Ertel. 1984. Role of endogenous opiates in the expression of negative feedback actions of androgen and estrogen on pulsatile properties of luteinizing hormone secretion in man. J. Clin. Invest. 74:47-55.

10. Wildt, L., A. Hausler, G. Marshall, J. S. Hutchison, T. M. Plant, P. E. Belchetz, and E. Knobil. 1981. Frequency and amplitude of gonadotropin-releasing hormone stimulation and gonadotropin secretion in the thesus monkey. Endocrinology. 109:376-385.

11. Clarke, I. J., J. T. Cummins, J. K. Findlay, K. J. Burman, and B. W. Doughton. 1984. Effects on plasma luteinizing hormone and follicle-stimulating hormone of varying the frequency and amplitude of gonadotropin-releasing hormone pulses in ovariectomized ewes with hypothalamo-pituitary disconnection. Neuroendocrinology. 39:214-221.

12. Valk, T. W., K. P. Corley, R. P. Kelch, and J. C. Marshall. 1980. Hypogonadotropic hypogonadism: hormonal responses to low dose pulsatile administration of gonadotropin-releasing hormone. $J$. Clin. Endocrinol. Metab. 51:730-738.

13. Crowley, W. F., and J. W. McArthur. 1980. Stimulation of the normal menstrual cycle in Kallman's syndrome by pulsatile administration of luteinizing hormone-releasing hormone (LHRH). J. Clin. Endocrinol. Metab. 51:173-175.

14. Hoffman, A. R., and W. F. Crowley. 1982. Induction of puberty in men by long-term pulsatile administration of low-dose gonadotropin-releasing hormone. N. Engl. J. Med. 307:1237-1241.

15. Spratt, D. I., J. S. Finkelstein, L. St. L. O’Dea, T. M. Badger, P. N. Rao, J. D. Campbell, and W. F. Crowley. 1986. Long-term administration of gonadotropin-releasing hormone in men with idiopathic hypogonadotropic hypogonadism. A model for studies of the hormone's physiologic effects. Ann. Intern. Med. 105:848-855.

16. Spratt, D. I., J. S. Finkelstein, J. P. Butler, T. M. Badger, and W. F. Crowley. 1987. Effects of increasing the frequency of low doses of gonadotropin-releasing hormone (GnRH) on gonadotropin secre- tion in GnRH-deficient men. J. Clin. Endocrinol. Metab. 64:11791186.

17. Kamel, F., J. A. Balz, C. L. Kubajak, and V. A. Schneider. 1987. Effects of luteinizing hormone (LH)-releasing hormone pulse amplitude and frequency on LH secretion by perifused rat anterior pituitary cells. Endocrinology. 120:1644-1650.

18. Katt, J. A., J. A. Duncan, L. Herbon, A. Barkan, and J. C. Marshall. 1985. The frequency of gonadotropin-releasing hormone stimulation determines the number of pituitary gonadotropin-releasing hormone receptors. Endocrinology. 116:2113-2115.

19. Clarke, I. J. and J. T. Cummins. 1985. GnRH pulse frequency determines $\mathrm{LH}$ pulse amplitude by altering the amount of releasable LH in the pituitary glands of ewes. J. Reprod. Fertil. 73:425-431.

20. Crowley, W. F., M. Filicori, D. Spratt, and N. Santoro. 1985. The physiology of gonadotropin-releasing hormone ( $\mathrm{GnRH}$ ) secretion in men and women. Recent Prog. Horm. Res. 41:473-531.

21. Spratt, D. I., D. B. Carr, G. R. Merriam, R. E. Scully, P. N. Rao, and W. F. Crowley. 1987. The spectrum of abnormal patterns of gonadotropin-releasing hormone secretion in men with idiopathic hypogonadotropic hypogonadism: clinical and laboratory correlations. $J$. Clin. Endocrinol. Metab. 64:283-291.

22. Spratt, D. I., W. F. Crowley, J. P. Butler, A. R. Hoffman, P. M. Conn, and T. M. Badger. 1985. Pituitary luteinizing hormone responses to intravenous and subcutaneous administration of gonadotropin-releasing hormone in men. J. Clin. Endocrinol. Metab. 61:890-895.

23. Spratt, D., L. St. L. O’Dea, D. Schoenfeld, J. Butler, P. N. Rao, and W. F. Crowley. 1988. Neuroendocrine-gonadal axis in men: frequent sampling of LH, FSH, and testosterone. Am. J. Physiol. 254 (Endocrinol. Metab. 17): E658-E666.

24. Nankin, H. R., and P. Troen. 1971. Repetitive luteinizing hormone elevations in serum of normal men. J. Clin. Endocrinol. Metab. 33:558-560.

25. Santen, R. J., and C. W. Bardin. 1973. Episodic luteinizing hormone secretion in man: pulse analysis, clinical interpretation, physiologic mechanisms. J. Clin. Invest. 52:2617-2628.

26. Badger, T. M. 1984. Perifusion of anterior pituitary cells: release of gonadotropins and somatotropins. Methods Enzymol. 124:79-90.

27. Filicori, M., J. P. Butler, and W. F. Crowley. 1984. Neuroendocrine regulation of the corpus luteum in the human: evidence for pulsatile progesterone secretion. J. Clin. Invest. 73:1638-1647.

28. Rao, P. N., and P. H. Moore. 1976. Synthesis of new steroid haptens for radioimmunoassay. 1. 15 $\alpha$-carboxymethylmercaptotestosterone-bovine serum albumin conjugate: measurement of testosterone in male plasma without chromatography. Steroids. 28:101-109.

29. Abraham, G. E., J. E. Buster, L. A. Lucas, D. C. Corrales, and R. C. Teher. 1972. Chromatographic separation of steroid hormones for use in radioimmunoassay. Anal. Lett. 8:509-517.

30. Liu, T. C. and G. L. Jackson. 1984. Long term superfusion of rat anterior pituitary cells: effects of repeated pulses of gonadotropinreleasing hormone at different doses, durations, and frequencies. Endocrinology. 115:605-613.

31. McIntosh, R. P., and J. E. A. McIntosh. 1983. Influence of the characteristics of pulses on gonadotropin releasing hormone on the dynamics of luteinizing hormone release from perifused sheep pituitary cells. J. Endocrinol. 98:411-421.

32. McIntosh, J. E. A., and R. P. McIntosh. 1986. Varying the patterns and concentrations of gonadotropin-releasing hormone stimulation does not alter the ratio of LH and FSH released from perifused sheep pituitary cells. J. Endocrinol. 109:155-161.

33. Wehmann, R. E., M. R. Blackman, and S. M. Harman. 1982. Metabolic clearance rates of luteinizing hormone in women during different phases of the menstrual cycle and while taking an oral contraceptive. J. Clin. Endocrinol. Metab. 55:654-659.

34. Pohl, C. R., D. W. Richardson, J. S. Hutchison, J. A. Germak, and E. Knobil. 1983. Hypophysiotropic signal frequency and the 
functioning of the pituitary-ovarian system in the rhesus monkey. Endocrinology. 112:2076-2080.

35. Plant, T. M., and Dubey A. K. 1984. Evidence from the rhesus monkey (macaca mulatta) for the view that negative feedback control of luteinizing hormone secretion by the testis is mediated by a deceleration of hypothalamic gonadotropin-releasing hormone pulse frequency. Endocrinology. 115:2145-2153.

36. Gross, K. M., A. M. Matsumoto, and W. J. Bremner. 1987. Differential control of luteinizing hormone and follicle-stimulating hormone secretion by luteinizing hormone-releasing hormone pulse frequency in man. J. Clin. Endocrinol. Metab. 64:675-680.

37. Adams, L. A., D. K. Clifton, W. J. Bremner, and R. A. Steiner. 1986. Testosterone modulates the differential release of LH and FSH that occurs in response to changing gonadotropin-releasing hormone frequency in the male monkey. Endocrinology. 118(Suppl.):151. (Abstr.)

38. Styne, D. M., and M. M. Grumbach. 1986. Puberty in the male and female: its physiology and disorders. In Reproductive Endocrinology. Physiology, Pathophysiology, and Clinical Management. S. S. C. Yen and R. B. Jaffe, editors. W. B. Saunders Company, Philadelphia. 313-384.

39. Spratt, D. I., and W. F. Crowley. 1988. Pituitary and gonadal responsiveness is enhanced during GnRH-induced puberty in the human. Am. J. Physiol. 254 (End̈ocrinol. Metab. 17): E652-E657.

40. Soules, M. R., R. A. Steiner, D. K. Clifton, N. L. Cohen, S. Aksel, and W. J. Bremner. 1984. Progesterone modulation of pulsatile luteinizing hormone secretion in normal women. J. Clin. Endocrinol. Metab. 58:378-383. 